\title{
Kinetic Resolution of Enantiomers in Enantiomerically Enriched 2-Alkanol by Pseudomonas cepacia Lipase Catalyzed Transesterification with Vinyl Acetate in Organic Solvent
}

\author{
Hirofumi Hirata ${ }^{1 *}$, Masako Ohno ${ }^{2}$, Keiyo Kawauchi ${ }^{1}$, Motomi Mayama ${ }^{1}$, \\ Yun-Gang Chen ${ }^{3}$, Hiroshi Yanagishita ${ }^{4}$ and Naoki KaMo ${ }^{2}$ \\ ${ }^{1}$ Department of Bioscience and Technology, School of Engineering, Hokkaido Tokai University \\ (5-1 Minamisawa, Minami-ku, Sapporo 005-8601, JAPAN) \\ ${ }^{2}$ Graduate School of Pharmaceutical Sciences, Hokkaido Univsersity \\ (Kita 12-Jo, Nishi 12-Chome, Kita-ku, Sapporo 060-0812, JAPAN) \\ ${ }^{3}$ Research Institute of Higher Education Programs, Hokkaido Tokai University \\ (5-1 Minamisawa, Minami-ku, Sapporo 005-8601, JAPAN) \\ ${ }^{4}$ AIST Tsukuba Central 5, National Institute of Advanced Industrial Science \\ (1-1 Higashi, Tsukuba 305-8565, JAPAN)
}

Edited by Y. Totani, Seikei Univ., and accepted October 22, 2002 (received for review September 27, 2002)

\begin{abstract}
Kinetic resolution of $(R)$ - and (S)-2-alkanols by Pseudomonas cepacia lipase catalyzed transesterification has been studied using vinyl acetate as an acetylating reagent, six 2alkanols and three organic solvents. The optical resolution of $(S)$-2-alkanol with enantiomeric excess $(e e)>95 \%$ was attained by controlling the extent of conversion, but $(R)$-2-alkanol with $e e>95 \%$ could not resolved from the racemate due to the moderate enantioselectivity. New equations as functions of the optical resolution data were introduced for predicting the ee values of enantiomers resolved by the transesterification with enantiomerically enriched 2-alkanol and they were experimentally verified: the predicted and experimentally obtained $e e$ values showed an excellent agreement in all systems studied. Based on these observations, optically pure $(R)$ and $(S)$-2-alkanols ( $e e \geqq 99 \%$ ) were resolved from the racemates in a preparative scale by repeating the transesterification.
\end{abstract}

Key words: Pseudomonas cepacia lipase (PCL), transesterification with vinyl acetate, kinetic resolution, enantiomerically enriched substrate, optically pure 2alkanol

\section{Introduction}

According to the optical resolution theory (1-3), the enantioselectivity ( $E$ : the enatiomeric ratio) is expressed as Eq. (1) when the enzymatic reaction is reversible:

$$
E=\frac{\ln \left[1-(1+K) c\left(1+e e_{\mathrm{P}}\right)\right]}{\ln \left[1-(1+K) c\left(1-e e_{\mathrm{P}}\right)\right]}
$$

$$
=\frac{\ln \left[1-(1+K)\left(c+e e_{\mathrm{S}}\{1-c\}\right)\right]}{\ln \left[1-(1+K)\left(c+e e_{\mathrm{S}}\{1+c\}\right)\right]}
$$

where $K$ is the equilibrium constant, $c$ is the extent of conversion, and $e e_{\mathrm{P}}$ and $e e_{\mathrm{S}}$ are optical purities in enantiomeric excess of the product and the unreacted substrate, respectively. When the reaction is irreversible or the reverse reaction is negligible $(K=0)$, Eq. ( 1$)$ is reduced to Eq. (2).

\footnotetext{
*Correspondence to: Hirofumi HiRATA, Department of Bioscience and Technology, School of Engineering, Hokkaido Tokai University, 5-1 Minamisawa, Minami-ku, Sapporo 005-8601, JAPAN

E-mail: hirata@db.htokai.ac.jp
} 


$$
E=\frac{\ln \left[1-c\left(1+e e_{\mathrm{P}}\right)\right]}{\ln \left[1-c\left(1-e e_{\mathrm{P}}\right)\right]}=\frac{\ln \left[(1-c)\left(1-e e_{\mathrm{S}}\right)\right]}{\ln \left[(1-c)\left(1+e e_{\mathrm{S}}\right)\right]}
$$

Kinetic resolution of chiral compounds with $e e>95 \%$ is considered to be important in a practical sense. For satisfying it, $E$ should be above 150 for the optical resolution at $c=0.5$ even though the reaction is irreversible [Eq. (2)]. If the reaction is reversible, for example in the case of $K=0.02$ [Eq. (1)], above 210 of $E$ is required at $c=0.5$. Such cases are not necessarily obtained for the common enzymatic reaction because available enzymes are limited and the enantioselectivity is also restricted. Thus, kinetic resolution from enantiomerically enriched substrates becomes important for the preparation of highly enantiomerically enriched compounds.

The problem is how to confirm the conversion $(c \%)$ that the reaction should be stopped and predict the optical purities $(e e)$ of enantiomers resolved from the enantiomerically enriched substrate. When enzymatic reactions are irreversible and their optical resolution data obey Eq. (2), the optical purity of fast-reacting enantiomer is predicted by

$$
\left[1-c\left(\frac{1+e e_{\mathrm{P}}^{\prime}}{1+e e_{0}}\right)\right]=\left[1-c\left(\frac{1-e e_{\mathrm{P}}^{\prime}}{1-e e_{0}}\right)\right]^{E}
$$

where $e e_{0}$ and $e e_{\mathrm{P}}{ }^{\prime}$ are optical purities of the starting substrate and the product, and $c^{\prime}$ is the extent of conversion based on the starting substrate (4). Similarly we obtained

$$
\left[\frac{(1-c)\left(1-e e_{\mathrm{S}}^{\prime}\right)}{1+e e_{0}}\right]=\left[\frac{(1-c)\left(1+e e_{\mathrm{S}}{ }^{\prime}\right)}{1-e e_{0}}\right]^{E}
$$

for optical purity $\left(e e_{\mathrm{s}}{ }^{\prime}\right)$ of the unreacted substrate. Equations (3)-(4) are, however, restricted to the reaction of $E=0$ and $K=0$.

In the previous paper (5), we reported that lipase (triacylglycerol hydrolase, EC 3.1.1.3) catalyzed transesterification between tributyrylglycerol (TB) and secondary alcohol was reversible in organic solvent and that the optical resolution data satisfied Eq. (1). Recently, it was reported that $E$ determined by Eq. (2) showed the maximum against $c$, i.e., the resolution data did not obey Eq. (1) nor Eq. (2) in Pseudomonas cepacia lipase (PCL) catalyzed transesterification between vinyl acetate (VA) and 2-alkanol (1) (Scheme 1) (6).

Thus, we selected the reaction in Scheme 1, introduced new equations for predicting the optical purities of enantiomers resolved from enatiomerically enriched substrate and investigated the titled resolution to obtain optically pure (1) (ee $\geqq 99 \%)$. In this paper, individual 2-alkanol was abbreviated to $\mathrm{X} 2-\mathrm{OH}$, where $\mathrm{X}$ is carbon number of the alcohol and 2- shows the position of hydroxy group, and its acetate was also abbreviated to $\mathrm{X} 2-\mathrm{OAc}$.

\section{Experimental}

\subsection{Materials}

Chemical reagents [vinyl acetate (VA), triacetylglyc-

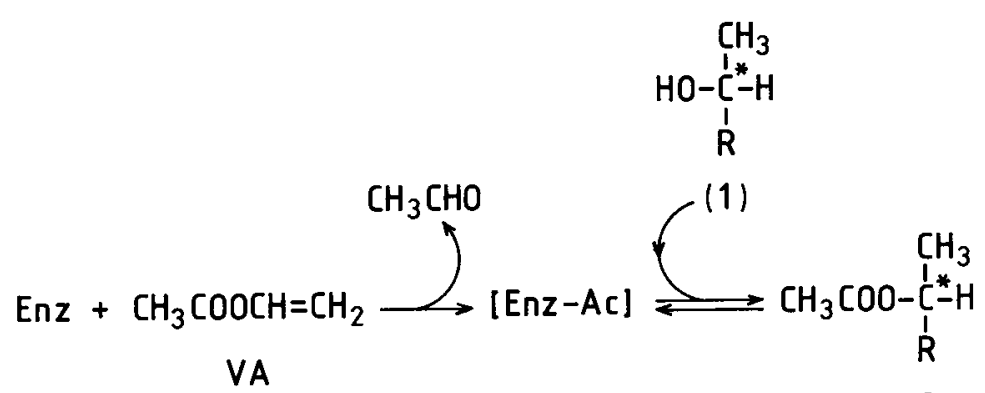

(2)

Enz : Pseudomonas cepacia Lipase (PCL)

2-Alkanol (Abbreviation)

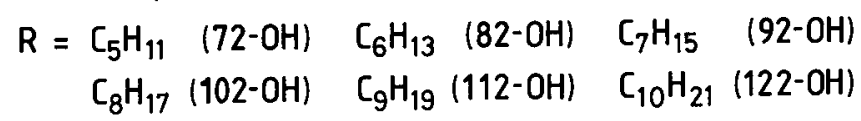

Scheme 1 
erol (TA), 2-alkanol (1) and (R)-1-(1-naphthyl)ethyl isocyanate], solvents, silica gel and PCL (43 U/mg) were used as received or after purification (6).

\subsection{Kinetic Resolution from Enantiomeri- cally Enriched Alcohol}

\section{$2 \cdot 2 \cdot 1 \quad$ Reaction with VA}

To a stirred solution $(33 \mathrm{~mL})$ containing VA $(1.53 \mathrm{M})$ $\left(1 \mathrm{M}=1 \mathrm{~mol} \mathrm{dm}^{-3}\right)$ and enantiomerically enriched 2alkanol $\left[(R)\right.$-enriched-(1) $\left(e e_{0}=0.40-0.86\right)$ or $(S)$ enriched-(1) $\left.\left(e e_{0}=0.40-0.71\right)\right](0.39-0.63 \mathrm{M})$ at $30^{\circ} \mathrm{C}$ was added PCL powder $(50-100 \mathrm{mg} / \mathrm{mL})$ and the stirring was continued. The time course was followed by $\mathrm{GC}$ and the reaction was terminated by filtration at the desired conversion. The reaction mixture was treated by a similar method as described in the previous paprer (6). Similarly the resolution from $(R S)-(\mathbf{1})$ was carried out.

\section{$2 \cdot 2 \cdot 2 \quad$ Reaction with TA}

PCL $(3.30 \mathrm{~g}, 100 \mathrm{mg} / \mathrm{mL})$ was added to a stirred mixture $(33 \mathrm{~mL})$ of TA $(0.81 \mathrm{M})$ and enantiomerically enriched 2-octanol $\left[(R)\right.$-enriched 82-OH $\left(e e_{0}=0.40\right.$ $0.80)$ or $(S)$-enriched $\left.82-\mathrm{OH}\left(e e_{0}=0.40-0.80\right)\right](0.56 \mathrm{M})$ dissolved in 1,2-dichloroethane at $30^{\circ} \mathrm{C}$. The reaction mixture was filtered at the desired conversion (determined by GC). The reaction mixture was treated by a similar method as described in the previous paprer (6). Similarly the resolution from $(R S)-82-\mathrm{OH}$ was performed.

\section{2·3 Resolution of Optically Pure 2-Alkanol in a Preparative Scale}

$2 \cdot 3 \cdot 1 \quad$ Optically pure $(R)-(\mathbf{1})$

1st Reaction-To a stirred mixture of $(R S)-82-\mathrm{OH}$ (0.62 mol), VA (1.08 mol) and 1,2-dichloroethane (500 $\mathrm{mL})$ at $30^{\circ} \mathrm{C}$ was added PCL $(70 \mathrm{~g})$ and the stirring was continued. After $6.5 \mathrm{~h}$ (56\% of conversion), the reaction mixture was filtered and the enzyme was washed with three $150 \mathrm{~mL}$ portions of 1,2-dichloroethane. The filtrates were combined and evaporated. The residue was dissolved with $500 \mathrm{~mL}$ of hexane, left for 1-3 h, filtered and evaporated. This procedure was repeated twice for removing the crystalline impurities. The refined residue was divided into 7.1-7.2 g portions. Each portion was dissolved with $30 \mathrm{~mL}$ of benzene, loaded on a silica gel column (Silica gel 100g, $\phi 30 \times$ $600 \mathrm{~mm}$ ), and treated by a similar method described above $(2 \cdot 2 \cdot 1)$. As a result, we obtained $(R)-82-\mathrm{OH}$ $(e e=75 \%)$ and $(S)-82-\mathrm{OH}(e e=94 \%)$ in yields of 69 and $85 \%$, respectively. These compounds were used as the starting substrates in the following 2 nd and 3 rd reactions.

2nd Reaction-A mixture of $(R)-82-\mathrm{OH}(e e=75 \%$, $0.44 \mathrm{~mol}), \mathrm{VA}(0.78 \mathrm{~mol}), 1,2$-dichloroethane $(360 \mathrm{~mL})$ and PCL $(50 \mathrm{~g})$ was stirred at $30^{\circ} \mathrm{C}$ for $3.5 \mathrm{~h}(73 \%$ of conversion). The reaction mixture was treated by a similar method as described above (the 1st reaction and $2 \cdot 2 \cdot 1)$, giving $(R)-82-\mathrm{OH}(e e=95 \%)$ in a yield of $70 \%$.

$3 r d$ Reaction $-\mathrm{A}$ mixture of $(R)-82-\mathrm{OH}(e e=95 \%$, $0.30 \mathrm{~mol})$, VA $(0.43 \mathrm{~mol}), 1,2$-dichloroethane $(250 \mathrm{~mL})$ and PCL $(35 \mathrm{~g})$ was stirred at $30^{\circ} \mathrm{C}$ for $3 \mathrm{~h}(88 \%$ of con-

Table 1 A Preparative Scale Resolution of Optically Pure $(R)-(\mathbf{1})$ from $(R S)-(\mathbf{1})$ by PCL Catalyzed Transesterification with VA in 1,2-dichloroethane at $30^{\circ} \mathrm{C}$.

\begin{tabular}{|c|c|c|c|c|c|c|c|c|c|}
\hline \multirow{2}{*}{$(R)-(\mathbf{1})$} & \multicolumn{3}{|c|}{ 1st Reaction ${ }^{\text {a) }}$} & \multicolumn{3}{|c|}{ 2nd Reaction } & \multicolumn{3}{|c|}{ 3rd Reaction } \\
\hline & $c / \%$ & $\mathrm{Y} / \%$ & $e e_{\mathrm{P}} / \%$ & $c / \%$ & $\mathrm{Y} / \%$ & $e e_{\mathrm{P}} / \%$ & $c / \%$ & $\mathrm{Y} / \%$ & $e e_{\mathrm{P}} / \%$ \\
\hline $72-\mathrm{OH}$ & 53 & 52 & 76 & 77 & 51 & 96 & 86 & 52 & 99 \\
\hline $82-\mathrm{OH}$ & 56 & 69 & 76 & 73 & 70 & 95 & 88 & 63 & 99 \\
\hline $92-\mathrm{OH}$ & 52 & 88 & 68 & 79 & 78 & 97 & 88 & 78 & 99 \\
\hline $102-\mathrm{OH}$ & 53 & 97 & 75 & 79 & 69 & 96 & 87 & 78 & 99 \\
\hline $112-\mathrm{OH}$ & - & - & $81^{b)}$ & 76 & 83 & 98 & 89 & 71 & $>99$ \\
\hline $122-\mathrm{OH}$ & 53 & 99 & 84 & 79 & 75 & 98 & 88 & 72 & $>99$ \\
\hline
\end{tabular}

a) $\mathrm{VA}=1.08 \mathrm{~mol}, 72-\mathrm{OH}=0.69 \mathrm{~mol}, 82-\mathrm{OH}=0.62 \mathrm{~mol}, 92-\mathrm{OH}=0.56 \mathrm{~mol}, 102-\mathrm{OH}=0.51 \mathrm{~mol}$, $22-\mathrm{OH}=0.43 \mathrm{~mol}$ and $\mathrm{PCL}=70.0 \mathrm{~g}$. Similar reaction conditions were used in the $2 \mathrm{nd}$ and 3rd reactions. Y: Yield of isolated alcohol.

b) The stocked sample of our laboratory. 
version). The reaction mixture was treated by a similar method as described above. Finally we obtained optically pure $(R)-82-\mathrm{OH}$ with $99 \%$ of $e e$ in a yield of $63 \%$.

Similarly optically pure $(R)-(\mathbf{1})$ was resolved from $(R S)-(\mathbf{1})$ in a preparative scale. The results were summarized in Table 1.

\section{$2 \cdot 3 \cdot 2$ Optically pure $(S)-(\mathbf{1})$}

1 st Reaction is identical to the 1 st reaction for $(R)$ $82-\mathrm{OH}(2 \cdot 3 \cdot 1)$.

2nd Reaction-A mixture of $(S)-82-\mathrm{OH}(e e=94 \%$, $0.38 \mathrm{~mol})$, VA (0.68 mol), 1,2-dichloroethane $(315 \mathrm{~mL})$ and PCL $(22 \mathrm{~g})$ was stirred at $30^{\circ} \mathrm{C}$ for $19 \mathrm{~h}(28 \%$ of conversion). The reaction mixture was treated by a similar method as described above $(2 \cdot 2 \cdot 1$ and $2 \cdot 3 \cdot 1)$. As a result, we obtained optically pure $(S)-82-\mathrm{OH}$ with $e e>99 \%$ from the unreacted substrate in a yield of $78 \%$.

Table 2 A Preparative Scale Resolution of Optically Pure $(S)-(\mathbf{1})$ from $(R S)-(\mathbf{1})$ by PCL Catalyzed Transesterification with VA in 1,2dichloroethane at $30^{\circ} \mathrm{C}$ ).

\begin{tabular}{|c|c|c|c|c|c|c|}
\hline \multirow{2}{*}{$(S)-(\mathbf{1})$} & \multicolumn{3}{|c|}{ 1st Reaction ${ }^{\text {a) }}$} & \multicolumn{3}{|c|}{ 2nd Reaction $\left.{ }^{b}\right)$} \\
\hline & $c / \%$ & $\mathrm{Y} / \%$ & $e e_{\mathrm{S}} / \%$ & $c / \%$ & $\mathrm{Y} / \%$ & $e e_{\mathrm{S}} / \%$ \\
\hline 72-OH & 53 & 62 & 94 & 19 & 63 & $>99$ \\
\hline $82-\mathrm{OH}$ & 56 & 85 & 95 & 28 & 78 & $>99$ \\
\hline $92-\mathrm{OH}$ & 52 & 90 & 85 & 28 & 77 & $>99$ \\
\hline $102-\mathrm{OH}$ & 53 & 95 & 89 & 29 & 86 & $>99$ \\
\hline $112-\mathrm{OH}$ & - & - & $87^{b)}$ & 20 & 78 & $>99$ \\
\hline $122-\mathrm{OH}$ & 53 & 95 & 92 & 12 & 85 & $>99$ \\
\hline
\end{tabular}

a) The reaction conditions were described in Table 1 .

Y: Yield of isolated alcohol.

b) $\mathrm{PCL}=50 \mathrm{mg} / \mathrm{mL}$.

c) Stocked sample of our laboratory.
Similarly optically pure $(S)$-(1) was resolved from $(R S)-(\mathbf{1})$ in a preparative scale. The results were summarized in Table 2.

\subsection{Analytical Methods}

GC and HPLC analyses were carried out by the same methods as described in the previous paper (6). Optical rotations of optically pure $(R)$ - and $(S)-(\mathbf{1})$ were measured by a JASCO DIP-370 Polarimeter using sodium D line $(589 \mathrm{~nm})$ and mercury lines $(405-577 \mathrm{~nm})$ at $20^{\circ} \mathrm{C}$. The results were summaried in Table 3 .

\section{Results and Discussion}

\subsection{Optical Resolution Data}

First of all we examined the optical resolution data for PCL catalyzed transesterification between VA and $(R S)-82-\mathrm{OH}$ in 1,2-dichloroethane and compared them with those for TA (Scheme 2) to find out the difference between VA and TA as acetylating reagents. The results were shown in Fig. 1. The $e e_{\mathrm{P}}$ value decreased with $c$ in both reactions as expected. The decrease in $e e_{\mathrm{P}}$ for the reaction with VA (Fig. 1A) was, however, more sluggish than that for TA (Fig. 1B). This suggests that the reverse reaction in the former is less significant relative to that in the latter.

A characteristic observation is $e e_{\mathrm{P}}=e e_{\mathrm{S}}$ at $c=0.5$ in both reactions (Fig. 1). Based on the difinitions of $e e_{\mathrm{P}}$, $e e_{\mathrm{S}}$ and $c$,

$$
c=\frac{e e_{\mathrm{S}}}{e e_{\mathrm{p}}+e e_{\mathrm{S}}}
$$

was obtained. When $c=0.5$ in Eq. (5), $e e_{\mathrm{P}}=e e_{\mathrm{S}}$. A similar correlation was observed in all systems studied.

Table 3 Specific Rotation Values $\left.([\alpha]]^{\circ}\right)$ of Optically Pure $(R)-(\mathbf{1})$ and $(S)-(\mathbf{1})^{\mathrm{a}}$.

\begin{tabular}{|c|c|c|c|c|c|c|c|c|c|c|}
\hline \multirow{2}{*}{$\lambda / \mathrm{nm}^{\mathrm{d})}$} & \multicolumn{5}{|c|}{$(R)-(\mathbf{1})^{\mathrm{b})}$} & \multicolumn{5}{|c|}{$(S)-(\mathbf{1})^{\mathrm{c})}$} \\
\hline & 589 & 577 & 546 & 435 & 405 & 589 & 577 & 546 & 435 & 405 \\
\hline $72-\mathrm{OH}$ & -10 & -10 & -11 & -18 & -21 & 9 & 9 & 11 & 18 & 22 \\
\hline $82-\mathrm{OH}$ & -9 & -9 & -10 & -16 & -19 & 8 & 8 & 9 & 16 & 19 \\
\hline $92-\mathrm{OH}$ & -8 & -8 & -9 & -15 & -17 & 7 & 8 & 9 & 15 & 17 \\
\hline $102-\mathrm{OH}$ & -7 & -8 & -9 & -14 & -16 & 7 & 7 & 8 & 13 & 16 \\
\hline $112-\mathrm{OH}$ & -7 & -7 & -8 & -13 & -15 & 6 & 6 & 7 & 12 & 14 \\
\hline $122-\mathrm{OH}$ & -6 & -7 & -8 & -12 & -14 & 5 & 6 & 6 & 11 & 13 \\
\hline
\end{tabular}

a) $C=5(\mathrm{~g} / 100 \mathrm{~mL})$ in chloroform at $20^{\circ} \mathrm{C}$.

b) The optical purity was listed in Table $\mathbf{1}$.

c) The optical purity was listed in Table 2 .

d) $589 \mathrm{~nm}$ : Sodium lamp (D line). 577-405 nm: Mercury lamp. 


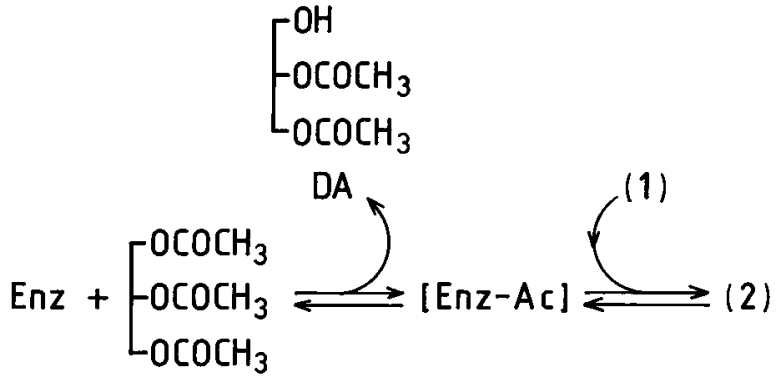

TA

\section{Scheme 2}

The notable difference between VA and TA was the dependence of $e e_{\mathrm{S}}$ on $c$ (Fig. 1). In the case of TA, $e e_{\mathrm{S}}$ decreased in the range of $c>0.65$ (Fig. 1B), which demonstrates that the reaction with TA is reversible. A similar reversibility has been reported in lipase catalyzed transesterification between TB and (1) in several organic solvents (7). The resolution data in Fig. 1B satisfied Eq. (1) with $E=18$ and $K=0.01$. In contrast, $e e_{\mathrm{S}}$ increased with $c$ in the reaction with VA (Fig. 1A). These again suggest that the reverse reaction for VA is less significant than TA. In PCL catalyzed transesterification, the reverse reaction is initiated by the competi- tive reaction of the free active serine residue in PCL between the acylating reagent and the product to give the acyl-enzyme intermediate [Enz-Ac]. In the case of VA, the intermediate reacts with unreacted $(R)$ - and $(S)$ $82-\mathrm{OH}$, in contrast, the intermediate reacts with the primary alcohol (DA) and unreacted $82-\mathrm{OH}$ in the transesterification with TA. It is generally recognized that primary alcohol reacts more rapidly than secondary alcohol in lipase catalyed reactions. Thus, the reverse reaction for TA becomes more significant than that for VA (Fig. 1).

From the above facts, we concluded that VA had an advantage for the optical resolution of $(S)$ isomer (the unreacted substrate) with higher $e e_{\mathrm{S}}$ relative to TA via PCL catalyzed transesterification. In addition, we should be borne in mind advantages of acceleration in the reaction rate (8) and easy removal of the unreacted acetylating reagent from the reaction mixture in the transesterification with VA.

\section{$3 \cdot 2$ Optical Resolution [Resolution from Racemate]}

Figure 1 suggests that $(S)-(\mathbf{1})$ with $e e>95 \%$ can be resolved from $(R S)-(\mathbf{1})$ by controlling $c$ of PCL cat-

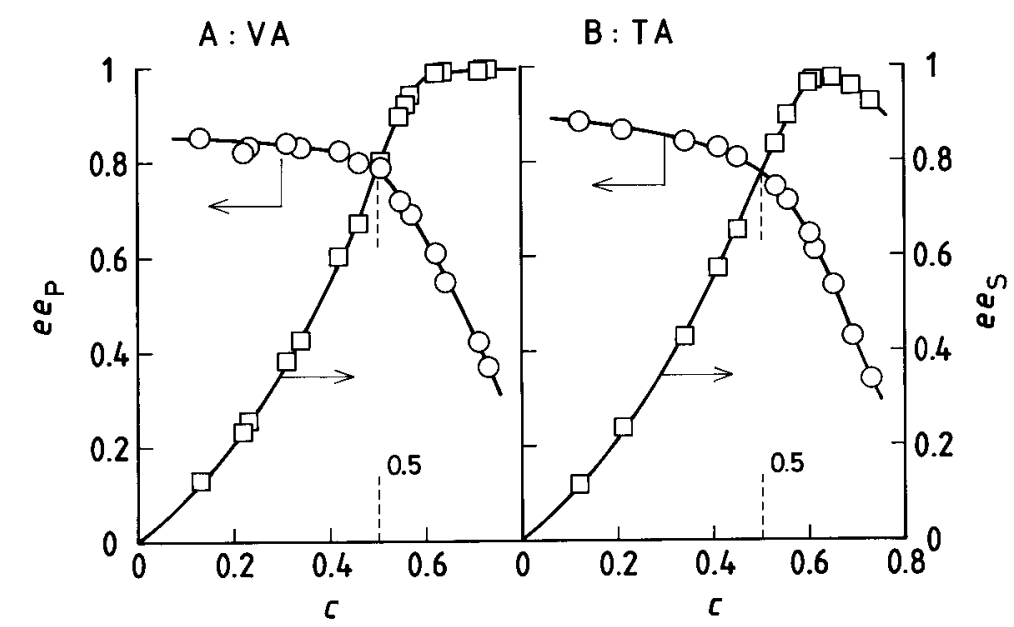

Fig. 1 Plots of ee vs. $c$ for PCL Catalyzed Transesterification with (RS)82-OH in 1,2-dichloroethane at $30^{\circ} \mathrm{C}$.

$\bigcirc: e e_{\mathrm{P}} v s . c, \square: e e_{\mathrm{S}} v s . c$

A : $[\mathrm{VA}]=0.98-1.63 \mathrm{M},[82-\mathrm{OH}]=0.56-0.93 \mathrm{M}$ and $\mathrm{PCL}=50$ $\mathrm{mg} / \mathrm{mL}$.

B : $[\mathrm{TA}]=0.76-1.33 \mathrm{M},[82-\mathrm{OH}]=0.56-0.77 \mathrm{M}$ and $\mathrm{PCL}=100$ $\mathrm{mg} / \mathrm{mL}$.

The resolution data in Fig. 1B fit Eq. (1) with $E=18$ and $K=0.01$. 
Table 4 Resolution of $(R)$ - and $(S)-(\mathbf{1})$ from $(R S)-(\mathbf{1})$ by PCL Catalyzed Transesterification with VA in Organic Solvent at $30^{\circ} \mathrm{C}^{\text {a) }}$.

\begin{tabular}{rccccccccc}
\hline & \multicolumn{3}{c}{ Hexane $^{\mathrm{a})}$} & \multicolumn{3}{c}{ 1,2-Dichloroethane $\mathrm{e}^{\mathrm{a})}$} & \multicolumn{3}{c}{ Acetonitrile $\mathrm{b})$} \\
\hline$(R)-(\mathbf{1})$ & $c / \%$ & $e e_{\mathrm{P}} / \%$ & $\left.E /-^{\mathrm{b}}\right)$ & $c / \%$ & $e e_{\mathrm{P}} / \%$ & $E /-^{\mathrm{b})}$ & $c / \%$ & $e e_{\mathrm{P}} / \%$ & $E /-^{\mathrm{b})}$ \\
\hline $72-\mathrm{OH}$ & 28 & 87 & 20 & 34 & 88 & 24 & 30 & 88 & 23 \\
$82-\mathrm{OH}$ & 27 & 78 & 11 & 33 & 81 & 14 & 28 & 82 & 13 \\
$92-\mathrm{OH}$ & 34 & 86 & 21 & 32 & 92 & 37 & 31 & 86 & 20 \\
$102-\mathrm{OH}$ & 31 & 80 & 13 & 34 & 84 & 17 & 32 & 84 & 17 \\
$112-\mathrm{OH}$ & 30 & 87 & 21 & 34 & 92 & 39 & 32 & 89 & 27 \\
$122-\mathrm{OH}$ & 33 & 90 & 27 & 33 & 94 & 53 & 34 & 91 & 33 \\
\hline$(R)-(\mathbf{1})$ & $c / \%$ & $e e_{\mathrm{S}} / \%$ & $\left.E /-^{\mathrm{b}}\right)$ & $c / \%$ & $e e_{\mathrm{S}} / \%$ & $E /-^{\mathrm{b})}$ & $c / \%$ & $e e_{\mathrm{S}} / \%$ & $E /-{ }^{\mathrm{b})}$ \\
\hline $72-\mathrm{OH}$ & 73 & $>99$ & 10 & 68 & $>99$ & 14 & 67 & $>99$ & 15 \\
$82-\mathrm{OH}$ & 72 & 98 & 9 & 65 & 99 & 14 & 69 & 99 & 11 \\
$92-\mathrm{OH}$ & 73 & 98 & 9 & 63 & 99 & 19 & 65 & 99 & 16 \\
$102-\mathrm{OH}$ & 73 & $>99$ & 10 & 66 & $>99$ & 16 & 69 & $>99$ & 14 \\
$112-\mathrm{OH}$ & 67 & $>99$ & 15 & 61 & $>99$ & 24 & 67 & $>99$ & 16 \\
$122-\mathrm{OH}$ & 72 & 99 & 10 & 64 & $>99$ & 18 & 71 & $>99$ & 11 \\
\hline
\end{tabular}

a) $[\mathrm{VA}]=1.63 \mathrm{M},[72-\mathrm{OH}]=0.63 \mathrm{M},[82-\mathrm{OH}]=0.56 \mathrm{M},[92-\mathrm{OH}]=0.51 \mathrm{M},[102-\mathrm{OH}]=0.46 \mathrm{M}$, $[112-\mathrm{OH}]=0.42 \mathrm{M},[122-\mathrm{OH}]=0.39 \mathrm{M}$ and $\mathrm{PCL}=30-50 \mathrm{mg} / \mathrm{mL}$.

b) Determined by Eq. (2).

alyzed transesterification with VA. In the previous papers, we reported that the reversibility, i.e., the reverse reaction, became critical in the optical resolution of $(S)$ isomer at high $c$ by PCL catalyzed transesterification with TB (7) and that $E$ determined by Eq. (2) was sharply decreased with $c$ in the range of $c>0.55$ in the transesterification with VA (6). In the consideration of these observations, we carried out the resolution of $(S)-(\mathbf{1})$ with $e e>95 \%$ from $(R S)$-(1) by PCL catalyzed transesterification with VA. The results were summarized in Table 4.

1,2-Dichloroethane and acetonitrile, which gave higher $E$ than the other solvents in the resolution from $(R S)-82-\mathrm{OH}(6)$, were used as the reaction solvents and hexane was also used as a standard solvent. Table 4 shows that $(S)-(\mathbf{1})$ with $e e>95 \%$ can be resolved from $(R S)$-(1) by controlling $c$ of the reaction with VA although in the expense of chemical yield.

As shownin Table 4, $(R)-(1)$ with $e e>95 \%$ could not be resolved from $(R S)-(\mathbf{1})$ in all cases because the enantioselectivity $(E)$ was not enough high for the optical resolution (see also Fig. 1A ).

\subsection{Kinetic Resolution from Enantiomeri- cally Enriched Substrate}

$3 \cdot 3 \cdot 1$ Introduction of new equations
In the previous paper (6), we reported that $E$ determined by Eq. (2) decreased with $c$ in the range of $c<0.5$ because acetylation of the $(S)$ isomer was surpressed during the reaction in PCL catalyzed transesterification between VA and (1): the pseudo first order plot with respect to enantiomer gave a linearity for $(R)-(\mathbf{1})$ but curveture for $(S)-(\mathbf{1})$. It was also reported that the optical resolution data fit Eq. (1) in lipase catalyzed transesterification between TB and secondary alcohol, i.e., the reaction is reversible $(5,7)$. A similar result was obtained for the reaction with TA (Fig. 1B). Recently, we found out that the pseudo first order plot gave curveture for both enantiomers in PCL catalyzed transesterification between TA and (RS)-82-OH in 1, 2-dichloroethane.

In the consideration of above observations, we introduced new equations for predicing the optical purities of enantiomers resolved from enantiomerically enriched substrate. Our idea is the use of optical resolution data because $e e_{\mathrm{P}}$ and $e e_{\mathrm{S}}$ are the functions of $E, K$ and $c$.

Equations for the Resolution of $(R)-(\mathbf{1})-$ In the previous paper (6), we reported that the optical resolution data were expressed as

$$
e e_{\mathrm{p}}=\frac{c_{\mathrm{R}}-c_{\mathrm{S}}}{c_{\mathrm{R}}+c_{\mathrm{S}}}
$$




$$
e e_{\mathrm{S}}=\frac{c_{\mathrm{R}}-c_{\mathrm{S}}}{2-\left(c_{\mathrm{R}}+c_{\mathrm{S}}\right)}
$$

and

$$
c=\frac{c_{\mathrm{R}}+c_{\mathrm{S}}}{2}
$$

where $c_{\mathrm{R}}$ and $c_{\mathrm{S}}$ are the extents of conversion of $(R)$ and $(S)-(\mathbf{1})$ in $(R S)-(\mathbf{1})$. In the enzymatic resolution, the reactions of enantiomers are simply expressed as

$$
\mathrm{A} \rightarrow \mathrm{P}
$$

and

$$
\mathrm{B} \rightarrow \mathrm{Q}
$$

where A and B are the fast- and slow-reacting enantiomers in $(R)$-enriched substrate (initial optical purity: $\left.e e_{0}\right)$, and $\mathrm{P}$ and $\mathrm{Q}$ are the products from $\mathrm{A}$ and $\mathrm{B}$, respectively. One can write down as follows:

$$
\begin{gathered}
e e_{0}=\frac{[\mathrm{A}]_{0}-[\mathrm{B}]_{0}}{[\mathrm{~A}]_{0}+[\mathrm{B}]_{0}} \\
e e_{\mathrm{P}}{ }^{\prime}=\frac{[\mathrm{P}]-[\mathrm{Q}]}{[\mathrm{P}]+[\mathrm{Q}]} \\
e e_{\mathrm{S}}{ }^{\prime}=\frac{[\mathrm{A}]-[\mathrm{B}]}{[\mathrm{A}]+[\mathrm{B}]}
\end{gathered}
$$

and

$$
c^{\prime}=\frac{[\mathrm{P}]+[\mathrm{Q}]}{[\mathrm{A}]_{0}+[\mathrm{B}]_{0}}
$$

where $[\mathrm{A}]_{0}$ and $[\mathrm{B}]_{0}$ are the initial concentrations of $\mathrm{A}$ and $\mathrm{B}, e e_{\mathrm{P}}{ }^{\prime}$ and $e e_{\mathrm{S}}{ }^{\prime}$ are optical purities of the product and the unreacted substrate and $c^{\prime}$ is the extent of conversion based on $(R)$-enriched substrate.

$$
\begin{aligned}
& \text { Let }[\mathrm{A}]_{0} /[\mathrm{B}]_{0}=r_{1} \text {, one obtains } \\
& e e_{0}=\frac{r_{1}-1}{r_{1}+1} \quad \text { or } \quad r_{1}=\frac{1+e e_{0}}{1-e e_{0}}
\end{aligned}
$$

Assuming that the extent of conversion is independent of the concentration, one obtaines

$$
c_{\mathrm{R}}=\frac{[\mathrm{P}]}{[\mathrm{A}]_{0}}
$$

and

$$
c_{\mathrm{S}}=\frac{[\mathrm{Q}]}{[\mathrm{B}]_{0}}
$$

Thus

$$
e e_{\mathrm{P}}{ }^{\prime}=\frac{r_{1} c_{\mathrm{R}}-c_{\mathrm{S}}}{r_{1} c_{\mathrm{R}}+c_{\mathrm{S}}}=\frac{e e_{0}+\frac{c_{\mathrm{R}}-c_{\mathrm{S}}}{c_{\mathrm{R}}+c_{\mathrm{S}}}}{1+e e_{0} \frac{c_{\mathrm{R}}-c_{\mathrm{S}}}{c_{\mathrm{R}}+c_{\mathrm{S}}}}=\frac{e e_{0}+e e_{\mathrm{P}}}{1+e e_{0} e e_{\mathrm{P}}}
$$

$$
\begin{aligned}
e e_{\mathrm{S}}{ }^{\prime}= & \frac{r_{1}\left(1-c_{\mathrm{R}}\right)-\left(1-c_{\mathrm{S}}\right)}{r_{1}\left(1-c_{\mathrm{R}}\right)+\left(1-c_{\mathrm{S}}\right)} \\
= & \frac{e e_{0}-\frac{c_{\mathrm{R}}-c_{\mathrm{S}}}{2-\left(c_{\mathrm{R}}+c_{\mathrm{S}}\right)}}{1-e e_{0} \frac{c_{\mathrm{R}}-c_{\mathrm{S}}}{2-\left(c_{\mathrm{R}}+c_{\mathrm{S}}\right)}}=\frac{e e_{0}-e e_{\mathrm{S}}}{1-e e_{0} e e_{\mathrm{S}}} \\
c^{\prime}= & \frac{r_{1} c_{\mathrm{R}}+c_{\mathrm{S}}}{r_{1}+1}=\frac{c_{\mathrm{R}}+c_{\mathrm{S}}}{2}+\frac{e e_{0}\left(c_{\mathrm{R}}-c_{\mathrm{S}}\right)}{2} \\
= & \frac{e e_{\mathrm{S}}\left(1+e e_{0} e e_{\mathrm{P}}\right)}{e e_{\mathrm{S}}+e e_{\mathrm{P}}}
\end{aligned}
$$

and

$$
c^{\prime}=\frac{e e_{0}-e e_{\mathrm{S}}^{\prime}}{e e_{\mathrm{P}}^{\prime}-e e_{\mathrm{S}}^{\prime}}
$$

where $e e_{\mathrm{S}}{ }^{\prime}>0$ and $e e_{\mathrm{S}}{ }^{\prime}<0$ mean that configurations of the unreacted substrate are $(R)$ and $(S)$, respectively.

Equations for the Resolution of (S)-(1)-Similarly we obtained optical purities of the product $\left(e e_{\mathrm{P}}{ }^{\prime \prime}\right)$ and the unreacted substrate $\left(e e_{\mathrm{S}}{ }^{\prime \prime}\right)$, and the extent of conversion $\left(c^{\prime \prime}\right)$ in the resolution from $(S)$-enriched substrate (initial optical purity: $\left.e e_{0}, r_{2}=[\mathrm{B}]_{0} /[\mathrm{A}]_{0}\right)$ :

$$
\begin{aligned}
& e e_{\mathrm{P}} "=\frac{[\mathrm{Q}]-[\mathrm{P}]}{[\mathrm{Q}]+[\mathrm{P}]}=\frac{r_{2} c_{\mathrm{S}}-c_{\mathrm{R}}}{r_{2} c_{\mathrm{S}}+c_{\mathrm{R}}}=\frac{e e_{0}-\frac{c_{\mathrm{R}}-c_{\mathrm{S}}}{c_{\mathrm{R}}+c_{\mathrm{S}}}}{1-e e_{0} \frac{c_{\mathrm{R}}-c_{\mathrm{S}}}{c_{\mathrm{R}}+c_{\mathrm{S}}}} \\
& =\frac{e e_{0}-e e_{\mathrm{P}}}{1-e e_{0} e e_{\mathrm{P}}} \\
& e e_{\mathrm{S}}{ }^{\prime}=\frac{[\mathrm{B}]-[\mathrm{A}]}{[\mathrm{B}]+[\mathrm{A}]}=\frac{r_{2}\left(1-c_{\mathrm{S}}\right)-\left(1-c_{\mathrm{R}}\right)}{r_{2}\left(1-c_{\mathrm{S}}\right)+\left(1-c_{\mathrm{R}}\right)} \\
& =\frac{e e_{0}+\frac{c_{\mathrm{R}}-c_{\mathrm{S}}}{2-\left(c_{\mathrm{R}}+c_{\mathrm{S}}\right)}}{1+e e_{0} \frac{c_{\mathrm{R}}-c_{\mathrm{S}}}{2-\left(c_{\mathrm{R}}+c_{\mathrm{S}}\right)}}=\frac{e e_{0}-e e_{\mathrm{S}}}{1+e e_{0} e e_{\mathrm{S}}}
\end{aligned}
$$

$$
\begin{aligned}
c^{\prime \prime}= & \frac{[\mathrm{Q}]+[\mathrm{P}]}{[\mathrm{B}]_{0}+[\mathrm{A}]_{0}}=\frac{r_{1} c_{\mathrm{S}}+c_{\mathrm{R}}}{r_{2}+1}=\frac{c_{\mathrm{R}}+c_{\mathrm{S}}}{2}-\frac{e e_{0}\left(c_{\mathrm{R}}-c_{\mathrm{S}}\right)}{2} \\
& =\frac{e e_{\mathrm{S}}\left(1-e e_{0} e e_{\mathrm{P}}\right)}{e e_{\mathrm{S}}-e e_{\mathrm{P}}}
\end{aligned}
$$

and

$$
c^{\prime \prime}=\frac{e e_{\mathrm{S}}{ }^{\prime \prime}-e e_{0}}{e e_{\mathrm{S}}{ }^{\prime \prime}-e e_{\mathrm{P}}{ }^{\prime \prime}}
$$

where $e e_{\mathrm{P}}{ }^{\prime \prime}>0$ and $e e_{\mathrm{P}}{ }^{\prime \prime}<0$ mean that configurations of the product are $(S)$ and $(R)$, respectively.

$3 \cdot 3 \cdot 2$ Resolution from $(R)$-enriched-(1)

As mentioned above, the kinetic resolution data $\left(e e_{\mathrm{P}}{ }^{\prime}\right.$, 


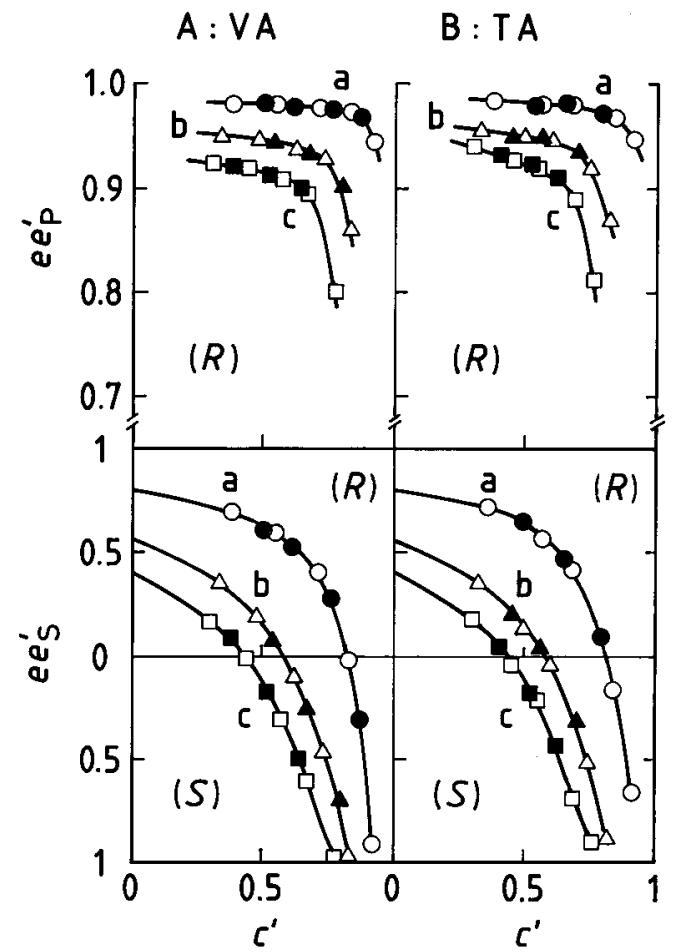

Fig. 2 Plots of $e e^{\prime} v s . c^{\prime}$ for PCL Catalyzed Transesterification with $(R)$-Enriched 82-OH in 1,2-dichloroethane $30^{\circ} \mathrm{C}$.

$e e_{0}:$ (a) 0.802 , (b) 0.554 and (c) 0.400 .

A : $[\mathrm{VA}]=1.63 \mathrm{M},[82-\mathrm{OH}]=0.56 \mathrm{M}$ and $\mathrm{PCL}=50$ $\mathrm{mg} / \mathrm{mL}$.

$\mathrm{B}:[\mathrm{TA}]=0.81 \mathrm{M},[82-\mathrm{OH}]=0.56 \mathrm{M}$ and $\mathrm{PCL}=100$ $\mathrm{mg} / \mathrm{mL}$.

$\bigcirc, \triangle, \square: e e^{\prime}\left(\right.$ calc) vs. $c^{\prime}($ calc $)$.

$\boldsymbol{O}, \boldsymbol{\Delta}: e e^{\prime}\left(\right.$ meas) vs. $c^{\prime}$ (meas). $e e_{\mathrm{S}}{ }^{\prime}$ and $c^{\prime}$ ) are able to be predicted by Eqs. (18)-(21) for the resolution from enantiomerically enriched substrate by enzymatic reaction. In order to verifiy these equations, we examined the resolution from $(R)$ enriched $82-\mathrm{OH}\left(e e_{0}=0.40-0.80\right)$ by PCL catalyzed transesterifications with VA and TA in 1,2dichloroethane. The results were illustrated in Fig. 2, which obviously shows an excellent agreement between the calculated $\left[e e^{\prime}(\right.$ calc $) v s . c^{\prime}($ calc $\left.)\right]$ and measured $\left[e e^{\prime}(\right.$ meas $) v s . c^{\prime}($ meas $\left.)\right]$ plots in both reactions. Figure 2 also shows that the conversion, at which one should terminate the reaction to obtain the product with a desired optical purity in a good chemical yield, can be estimated from the plots of $e e_{\mathrm{P}}^{\prime}$ (calc) vs. $c^{\prime}$ (calc) determined by Eqs. (18) and (20).

Based on the above observations and Eqs. (18)-(21), the starting material with at least $70 \%$ of $e e_{0}$, more favoritely $80 \%$ of $e e_{0}$, was required for the resolution of $(R)$-(1) with $e e \geqq 95 \%$. In order to prove it, we examined the resolution from $(R)$-enriched-(1) by the transesterification with VA. The results were summarized in Table 5. This also showed that the values of $e e_{\mathrm{P}}{ }^{\prime}$ (calc) determined by Eq. (18) were in an excellent accordance with those of $e e_{\mathrm{P}}{ }^{\prime}$ (meas).

The results in Fig. 2 and Table 5 demonstrate that Eqs. (18)-(21) are generally applicable to predict optical purities of enantiomers resolved from enantiomerically enriched substrate by enazymatic and catalytic reactions and that their equations are independent of reversibility/irreversibility of the reaction and of obedi-

Table 5 Kinetic Resolution of Highly Enantiomerically Enriched $(R)-(\mathbf{1})$ from $(R)$-enriched-(1) by PCL Catalyzed Transesterification with VA in Organic Solvent at $30^{\circ} \mathrm{C}$ a).

\begin{tabular}{|c|c|c|c|c|c|c|c|c|c|c|c|c|}
\hline \multirow{3}{*}{$(R)-(\mathbf{1})$} & \multicolumn{4}{|c|}{ Hexane } & \multicolumn{4}{|c|}{ 1,2-Dichloroethane } & \multicolumn{4}{|c|}{ Acetonitrile } \\
\hline & \multirow{2}{*}{$e e_{0} / \%$} & \multirow{2}{*}{$c^{\prime} / \%$} & \multicolumn{2}{|c|}{$e e_{\mathrm{P}} / \%^{\mathrm{b})}$} & \multirow{2}{*}{$e e_{0} / \%$} & \multirow{2}{*}{$c / \%$} & \multicolumn{2}{|c|}{$e e_{\mathrm{P}}^{\prime} / \%{ }^{\mathrm{b})}$} & \multirow{2}{*}{$e e_{0} / \%$} & \multirow{2}{*}{$c / \%$} & \multicolumn{2}{|c|}{$e e_{\mathrm{P}}^{\prime} / \%{ }^{\mathrm{b})}$} \\
\hline & & & meas & calc $^{\mathrm{c})}$ & & & meas & calc $^{c)}$ & & & meas & calc $^{\text {c) }}$ \\
\hline $72-\mathrm{OH}$ & 85 & 77 & 98 & 98 & 85 & 77 & 98 & 98 & 85 & 76 & 98 & 98 \\
\hline $82-\mathrm{OH}$ & 76 & 72 & 95 & 95 & 80 & 76 & 98 & 98 & 76 & 70 & 96 & 97 \\
\hline $92-\mathrm{OH}$ & 70 & 74 & 96 & 95 & 86 & 62 & 98 & 98 & 70 & 73 & 96 & 96 \\
\hline $102-\mathrm{OH}$ & 75 & 74 & 96 & 95 & 75 & 69 & 98 & 98 & 75 & 73 & 98 & 98 \\
\hline $112-\mathrm{OH}$ & 79 & 75 & 97 & 98 & 79 & 76 & 98 & 98 & 79 & 77 & 97 & 98 \\
\hline $122-\mathrm{OH}$ & 80 & 76 & 98 & 98 & 80 & 75 & 99 & 99 & 80 & 76 & 98 & 99 \\
\hline
\end{tabular}

a) $[\mathrm{VA}]=1.63 \mathrm{M},[72-\mathrm{OH}]=0.63 \mathrm{M},[82-\mathrm{OH}]=0.56 \mathrm{M},[92-\mathrm{OH}]=0.51 \mathrm{M},[102-\mathrm{OH}]=0.46 \mathrm{M}$, $[112-\mathrm{OH}]=0.42 \mathrm{M}, \quad[122-\mathrm{OH}]=0.39 \mathrm{M}$ and $\mathrm{PCL}=100 \mathrm{mg} / \mathrm{mL}$.

b) Errors were $\pm 1 \%$.

c) Determined by Eq. (18). 


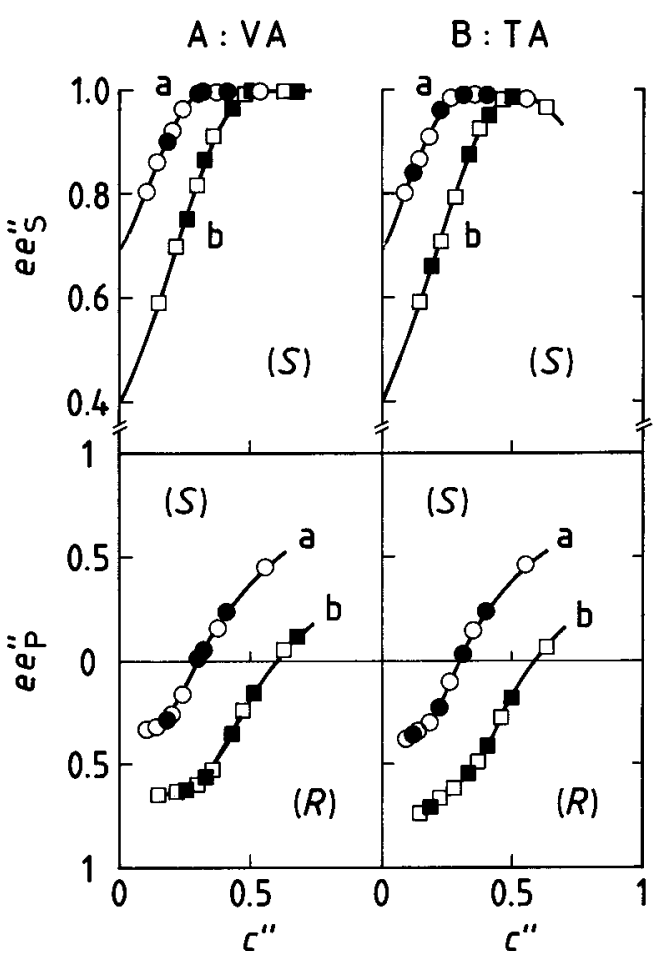

Fig. 3 Plots of $e e^{\prime \prime} v s . c^{\prime \prime}$ for PCL Catalyzed Transesterification with $(S)$-Enriched 82-OH in 1,2-dichloroethane at $30^{\circ} \mathrm{C}$.

$e e_{0}$ : (a) 0.694 and (b) 0.400 .

A : $[\mathrm{VA}]=1.63 \mathrm{M},[82-\mathrm{OH}]=0.56 \mathrm{M}$ and $\mathrm{PCL}=50$ $\mathrm{mg} / \mathrm{mL}$.

B : $[\mathrm{TA}]=0.81 \mathrm{M},[82-\mathrm{OH}]=0.56 \mathrm{M}$ and $\mathrm{PCL}=100$ $\mathrm{mg} / \mathrm{mL}$.

$\bigcirc, \square: e e^{\prime \prime}(\mathrm{calc}) v s . c^{\prime \prime}(\mathrm{calc})$.

, $: e e^{\prime \prime}$ (meas) vs. $c^{\prime \prime}$ (meas).

ence to the optical resolution theory [Eqs. (1)-(2)].

\section{$3 \cdot 3 \cdot 3$ Resolution $(S)$-enriched-(1)}

As shown in Table 4, (S)-(1) with $e e_{\mathrm{S}} \geqq 98 \%$ could be resolved by controlling $c$ of the reaction with VA. However, this method has a disadantage of low chemical yield. In the case of TA, the optical purity of $(S)$ $82-\mathrm{OH}$ was below $96 \%$ due to the reverse reaction (Fig. 1B). A similar tendency has been reported in lipase catalyzed transesterification with TB (7). In such cases, a useful strategy is the use of enantiomerically enriched substrate. Then, we examined the resolution of $(S)-(\mathbf{1})$ from $(S)$-enriched-(1) by the transesterifications.

As shown in Fig. 3, the plots of $e e^{\prime \prime}$ (meas) $v s$. $c^{\prime \prime}$ (meas) were in an excellent accordance with those of $e e^{\prime \prime}$ (calc) vs. $c^{\prime \prime}$ (calc) determined by Eqs. (22)-(25) and the disadvantages described above were relieved: opti- cally pure $(S)-(\mathbf{1})\left(e e_{\mathrm{S}}>99 \%\right)$ was recovered at low conversion, i.e., in a good chemical yield (Fig. 3A) and $e e_{\mathrm{S}}>99 \%$ was attained for the reaction with TA (Fig. $3 \mathrm{~B}$, curve a).

\subsection{Resolution of Optically Pure (R)- and $(S)-(1)$ in a Preparative Scale}

Finally we attempted the resolution of optically pure $(R)$ - and $(S)$-(1) (ee $\geqq 99 \%)$ from $(R S)$-(1) in a preparative scale by repeating the transesterification with VA in 1,2-dichloroethane. The results were summarized in Tables 1 and 2. The ee values of the resolved alcohols agreed with those determined by Eqs. (18)-(20) and (22)-(24). Optically pure $(R)-(1)$ was resolved by repeating the transesterification three times and twice for optically pure $(S)-(\mathbf{1})$. This procedure will useful for kinetic resolution of highly enantiomerically enriched fast reacting enatiomer in the racemate by enzymatic reactions with a moderate enantioselectivity and for the resolution of optically pure slow reacting enantiomer by the reversible enzymatic reactions.

The specific rotations of optically pure $(R)$ - and $(S)$ (1) were summaried in Table 3. The former is negative and positive for the latter. The absolute value of specific rotation decreased with carbon number of the alcohol and the wavelength.

\section{Conclusion}

New equations as functions of the optical resolution data were introduced for predicting optical purities of enantiomers resolved by PCL catalyzed tranesterification with enantiomerically enriched 2-alkanols and they were verified experimentally. The results in this paper demonstrate that the proposed equations are applicable to enzymatic and catalytic reactions and that they are independent of reversibility /irreversibility of the reactions and of obedience to the optical resolution theory [Eqs. (1) and (2)]. The present procedure will be a powerful strategy for the preparation of optically pure enantiomers from enatiomerically enriched substrates, especially the resolutions of fast-reacting enantiomer by the enzymatic reactions with a moderate enantioselectivity and slow-reacting enatiomer by the reversible enzymatic reactions. 


\section{References}

1. C.-S. CHEN, S.-H. WU, G. GIRDAUKAS and C.J. SIH, Quantitative Analyses of Biochemical Kinetic Resolution of Enantiomers. 2. Enzyme-Catalyzed Esterification in Water-Organic Solvent Biphasic Systems, J. Am. Chem. Soc., Vol. 109, $2812-$ 2817 (1987).

2. C.-S. CHEN and C.J. SIH, General Aspect and Optimization of Enantioselective Biocatalysis in Organic Solvents: The Use of Lipases, Angew. Chem. Int. Ed. Engl., Vol. 28, 695-707 (1989).

3. C.-S. CHEN and Y.-C. LIU, Stereochemical Recognition in Lipase Catalysis, Yukagaku, Vol. 41, 724-733 (1992).

4. C.-S. CHEN, Y. FUJIMOTO, G. GIRDAUKAS and C.J. SIH, Quantitative Analyses of Biochemical Kinetic Resolutions of Enantiomers, J. Am. Chem. Soc., Vol. 104, 7294-7299 (1982).

5. H. HIRATA, M. MAYAMA, N. INADA, K. YAMADA, H. YANAGISHITA and M. SUGIURA, Kinetics on the Optical Resolution of 2-Octanol in Tributyrylglycerol by Lipase-Cat- alyzed Transesterification, Yukagaku, Vol. 44, 1067-1074 (1995).

6. M. OHNO, N. KAMO, T. KITAMOYTO, N. YAMAZATO, N. HOSHIBA, M. MAYAMA and H. HIRATA, Kinetic Studies on the Optical Resolution of 2-alkanol by Pseudomonas cepacia Lipase Catalyzed Transesterification with Vinyl Acetate in Organic Solvent, J. Oleo Sci., Vol. 51, 643-653 (2002).

7. Y.-F. WANG, J.J. LALONDE, M. MOMONGAN, D.E. BERGBREITER and C.-H. WONG, Lipase-Catalyzed Irreversible Transesterification Using Enol Esters as Acylating Reagents; Preparative Enantio- and Regioselective Syntheses of Alcohols, Glycerol Derivatives, Sugars, and Organometallics, J. Am. Chem. Soc., Vol. 110, 7200-7205 (1988).

8. H. HIRATA, M. MAYAMA, A. KASAHARA, H. YANAGISHITA and M. SUGIURA, Analysis of Kinetic Resolution Data in Lipase Catalyzed Transesterification between Tributyrylglycerol and 2-Alkanols in Organic Solvents, J. Jpn Oil Chem. Soc., Vol. 45, 761-767 (1996). 